\title{
Illustrated examples of the effects of risk preferences and expectations on bargaining outcomes
}

David L. Dickinson

\begin{abstract}
The author highlights bargaining examples that use expected utility theory. Bargainer payoffs in the event of a dispute are represented by a simple lottery. Expectations are assumed to affect a bargainer's subjective probabilities over lottery outcomes, and risk preferences affect the expected utility of a given lottery. Risk preferences and/or expectations are predicted to influence both negotiated outcomes and the likelihood of a bargaining impasse. The analysis shows that, ceteris paribus, risk aversion or pessimism, or both, will cause a bargainer to capture less of the pie in negotiations. Similarly, risk-loving and optimistic bargainers are more likely to experience impasse because of the disappearance of the contract zone. The results are intuitive, can be shown graphically and algebraically, and provide upper-level students with engaging examples that show the usefulness of expected utility theory.
\end{abstract}


A common topic covered in most intermediate microeconomics classes is consumer choice under uncertainty. Once students have been exposed to expected utility theory, instructors often illustrate the usefulness of that analytical tool by means of some standard examples (e.g., choices over fair gambles and optimal insurance coverage). In this article, I highlight another class of applied problems that can be explored with expected utility theory. Specifically, I show how the tools of expected utility theory can be exploited to discuss bargaining outcomes and the likelihood of failed negotiations. This is an easy topic to motivate discussion given the pervasiveness of bargaining situations in real life. Negotiating the price of a car, house, or wage contract are all common bargaining contexts. Negotiations also range from small stakes (haggling over the price of a small item at a flea market) to very large stakes (international trade negotiations). To the extent that simple two-person bargaining over one disputed item is a building block for more complicated negotiations, the simple approach in this article can motivate discussion on a wide variety of bargaining contexts.

The examples discussed in this article require the understanding of expected utility theory that is taught using the basic diagram of a utility function [i.e., the graph in $\mathrm{xU}(\mathrm{x})$ space]. As such, these examples would be appropriate for students of intermediate and advanced microeconomics, as well as advanced-level students in courses where bargaining is of interest (e.g., labor economics, labor relations, and game theory).

The approach I use is to assume that outcomes in the event of failed negotiations-bargaining impasse-are uncertain and represented by a lottery. I present graphical and numeric examples of how expectations over impasse lotteries and risk preferences influence bargaining outcomes and the likelihood of impasse. Many complexities of negotiations are ignored when one focuses only on expectations and risk preferences. Further, two-person bargaining is obviously more complicated than individual choice analysis. Nevertheless, by isolating the decision of each bargainer, expected utility theory can be useful in examining how risk preferences and expectations alter bargaining outcomes. In this article, I highlight an engaging set of examples not usually exploited for upper-level students. These examples can be covered in an entirely graphical fashion, or instructors can also cover the algebraic solutions. Calculus is not required of the students to comprehend the concepts.

\section{MOTIVATING INTUITION}

It is often useful for students to first think through the intuition of a problem before commencing the analysis. The intuition of how expectations and risk preferences might affect bargaining outcomes is simple. First, the more (less) risk averse a bargainer is, the less (more) favorable a negotiated outcome will probably be. Second, the more (less) pessimistic a bargainer is about the outcome in the event of a bargaining impasse, the less (more) favorable a negotiated outcome will probably be. For this article, risk aversion refers to the simple notion of a concave (in wealth or in the outcome of the negotiations) utility function; pessimism refers to placing a higher subjective probability on the less favorable outcome of the impasse lottery. In labor negotiations, for example, this impasse lottery might represent the uncertainty of going on strike, 
of letting an arbitrator impose a settlement, or of moving to the next stage of bargaining (where stakes may be much higher).

Researchers have shown interest in examining how expectations or risk preferences, or both, affect bargaining outcomes. Negotiator optimism of some sort has been examined theoretically in Shavell (1982), Priest and Klein (1984), and empirically in Farmer, Pecorino, and Stango (2001), Neale and Bazerman (1985), and Babcock, Loewenstein, Issacharoff, and Camerer (1995).[1] The theoretical work in this area has shown that the bargainers' contract zone (i.e., the region of settlements that both parties prefer over impasse) may disappear as a result of divergent expectations of the bargaining outcome. In the empirical studies, Neale and Bazerman (1985) used a simulated contract negotiation to show, among other things, that overconfident subjects exhibit less successful performance. Babcoc, et al. (1995) showed that individuals process information in a self-serving way that contributes to a bargaining impasse even with common information. Farmer, Pecorino, and Stango (2001) analyzed field data from major league baseball and found that excessive player optimism is a likely cause of failed negotiations that result in salary arbitration.

Risk preferences have also been a key variable in many bargaining models. Farber and Katz (1979) showed how risk aversion (along with uncertainty as to what an arbitrator might decide) increases the size of negotiators' contract zone, whereas uncertainty as to the outcomes expected from failed negotiations also increases the contract zone size. Crawford (1982) also found that negotiated settlements favor the less risk-averse bargainer. Others have generated data from student subjects and found some support for the hypothesis that risk aversion weakens a bargainer's negotiated outcome, even in relatively small stakes experiments (Murnighan, Roth, and Shoumaker 1988; Farber, Neale, and Bazerman 1990).[2]

The results from existing research can be summarized as follows. Risk aversion, ceteris paribus, enlarges the contract zone and therefore makes agreement more likely, but negotiated agreements are then likely to favor the less risk-averse bargainer.[3] Also, a pessimistic expectation of outcomes in failed negotiations will enlarge the contract zone but promote a lessfavorable settlement for the more-pessimistic bargainer. Note that this further implies that riskloving preferences and optimistic expectations are likely to cause bargaining impasse. 


\section{FRAMEWORK}

I first establish a bargaining framework by assuming that two individuals are engaged in zerosum bargaining. [4] Bargainer $X$ enjoys higher utility for higher values of $X$, and bargainer $Y$ enjoys higher utility for higher values of $y$. To make this a zero-sum negotiation, assume that the bargainers are disputing over the division of a pie of size 200 (for example), such that $x+y=$ 200. It is apparent that this is a distributive (win-loss) bargaining framework because bargainer $X$ enjoys more of the pie at the expense of bargainer $Y$ and vice versa. As a first example, I assume that bargainer $X$ is risk averse and has utility function

$$
U(x)=\sqrt{x}
$$

I also assume that bargainer $\mathrm{Y}$ is risk neutral, with utility function $\mathrm{U}(\mathrm{y})=\mathrm{y}$. Throughout, I also assume that risk preferences (and expectations) are common knowledge, because an additional potential source of bargaining failure would otherwise arise from asymmetric information (see Farmer and Pecorino 1994).

Having described the risk preferences of the bargainers, I now describe their expectations of the lottery they face in the event of failed negotiations. By describing negotiations in this fashion, I am not explicitly modeling any negotiations process. Rather, I am highlighting a snapshot of a particular moment in time where the bargainers have particular expectations of the risks of not negotiating a settlement at that point. Because I have described a pie of size 200 , I might assume that each bargainer would expect that an impasse outcome could be lower or higher than $x=y=100$-a split-the-difference outcome. Suppose that bargainer X's expectation of the lottery in the event of an impasse (e.g., arbitration) is a 50 percent chance of an outcome of 50 and a 50 percent chance of an outcome of 150. Suppose that bargainer $Y$ has the same expectations of the lottery.

The graphs in Figure la show each bargainer's utility function, along with their respective certainty equivalents for the lottery they face.[5] The certainty equivalent is just the amount that the bargainer would be willing to accept, with certainty, to be indifferent between the lottery (gamble) and the certain payment. This certainty equivalent can also be referred to as the threat point (or reservation value), because it represents the minimum an individual would accept in a negotiated outcome. Graphically, students can trace from the expected x outcomes (top panel of Figure 1a) up to the utility function and then over to the $U(x)$ to find the utility of each possible contingency. The expected utility of a 50-50 lottery is just midway between these two points on the vertical axis, or .5U(50) $+.5 \mathrm{U}(150)$. Having found that point, I can trace that point back to the utility function and straight down to the $x$ axis to find the amount of $x$ that, given with certainty, would provide bargainer $X$ with the same utility as the 50-50 lottery over outcomes of $x$ $=50$ and $x=50$. It is apparent that this certainty equivalent, which is the minimum amount that bargainer $X$ would be willing to accept in negotiations to avoid the gamble, is less than the expected value of the lottery for a risk-averse bargainer. This is important because it means that the key point can be highlighted purely graphically. More formally, the certainty equivalent in this example for bargainer $\mathrm{X}$ is 


$$
.5 U(50)+.5 U(150)=.5 \sqrt{50}+.5 \sqrt{150}=9.66
$$

(the expected utility of the gamble).

Next, find the value of $x$ such that $U(x)=9.66$.

$$
\sqrt{x}=9.66 \text { or } x=(9.66)^{2} \text {, }
$$

which implies that $x=93$ is the approximate certainty equivalent.

The same procedure can be followed for the risk-neutral bargainer $Y$ in our example to show that the certainty equivalent is $y=100$ for this bargainer (see the bottom panel of Figure 1a). Having done that, students can now find the contract zone of mutually acceptable outcomes by integrating this information from both bargainers. Keeping in mind that the certainty equivalent represents the minimum amount that the bargainer would be willing to accept in order to avoid the lottery, bargainer $X$ would be willing at this point to accept anything from $x=93$ to $x=200$, which implies giving bargainer $Y$ anywhere from 107 to 0 of the pie, respectively. Bargainer $Y$ would be willing to accept anything from $y=100$ to $y=200$, which implies giving bargainer $X$ from 100 to 0 of the pie. This information can be graphed together, as has been done in Figure $1 \mathrm{~b}$-it could also be done on bargainer Y's set of axes if one chooses. By joining this information together, one can easily see whether the acceptable outcomes overlap to create a contract zone of mutually acceptable outcomes. In this example, the contract zone is from $x=93$ to $x=$ 100 (or $y=100$ to $y=107$ ). For simplicity, the instructor can assume that the midpoint of this range (e.g., 96.5) would be the actual negotiated outcome.[6]

This first example highlights a key point: The negotiated outcome will likely favor the risk-neutral bargainer over the risk-averse bargainer. Another example could be created with a bargainer $Y$ who is more risk averse than bargainer $X$ to show that the contract zone favors the less riskaverse bargainer.[7]

The certainty equivalent for a risk-loving bargainer $Y$ with $U(y)=y^{\wedge}$ sup $2^{\wedge}$ appears in Figure 2a. Again assuming the same expectations of a 50-50 lottery over the outcomes of $y=50$ or $y=$ 150 , I can calculate the bargainer's certainty equivalent as being approximately $y=112$. The prediction of bargaining impasse (i.e., failed negotiations) if this risk-loving bargainer $Y$ is matched with a risk-averse bargainer $X($ with $U(x)=$ [the square root of $\mathrm{X}$ ) is shown in Figure $2 \mathrm{~b}$. In this case, there is no overlap to the bargainers' acceptable outcomes, and so no contract zone exists-the prediction is that negotiations fail and no agreement will be made. With just these two examples in Figures 1 and 2, one can see how risk preferences play a critical role in the likelihood of an agreement and, if agreement is likely, whom the agreement will favor.

The second key variable to highlight is the bargainers' expectations. The instructor may actually choose between two different ways to approach the issue of optimistic or pessimistic expectations. First, one could assume that the same possible impasse outcomes-50 and 150are likely, but a pessimistic bargainer $X$ might assume that the probability of an outcome of $x=$ 50 is perhaps 75 percent (so there is a 25 percent chance of an outcome of $x=150$ ). Intuitively, 
one would expect this to lower bargainer X's certainty equivalent, which it does. However, the same could be accomplished by preserving the odds of the gamble while changing the two impasse outcomes. For example, another way in which bargainer $X$ could be assumed pessimistic is that his or her expectations are that the lottery he or she faces now has a 50 percent chance of $x=25$ and a 50 percent chance of $x=125$.[8] The instructor can choose either approach in discussing expectations because they both accomplish the same purpose from a practical standpoint. A bargainer with optimistic expectations would, of course, be created by placing a higher probability on the more favorable impasse outcome, or by raising the higher impasse outcome for a given expected probability.

A final graphical example to show how altered expectations can affect bargaining outcomes is presented in Figure 3. Here, I assume that bargainer $Y$ is risk neutral and neutral in expectations (as before)-expecting a 50 percent chance of a $y=50$ outcome and a 50 percent chance of a $y=150$ outcome. Bargainer $X$ is risk averse, with

$$
U(x)=\sqrt{x}
$$

but is also pessimistic in expectations. Bargainer $X$ expects a 75 percent chance of an $x=50$ outcome and only a 25 percent chance of an $x=150$ outcome in the event of an impasse. As such, bargainer $Y$ 's certainty equivalent is $y=100$ as before, but bargainer X's certainty equivalent can be calculated as approximately $x=70$ (Figure 3a). The resultant contract zone (Figure $3 b$ ) is from $x=70$ to $x=100$ so that a midpoint negotiated outcome would be at $x=85$ $(y=115)$. Note that compared with the examples in Figure 1, the pessimistic expectations of bargainer $X$, which widen the contract zone in bargainer Y's favor, are responsible for skewing the likely negotiated outcome even more in bargainer Y's favor when compared to our first example (Figure $1 b)$ where bargainer $X$ is risk averse but not pessimistic. This framework can also be used to highlight how optimism may cause bargaining failure (by shrinking or eliminating the contract zone), a point noted in the existing literature (e.g., Neale and Bazerman 1985; Babcock and Loewenstein 1997; Farmer, Pecorino, and Stango 2001).[9] 


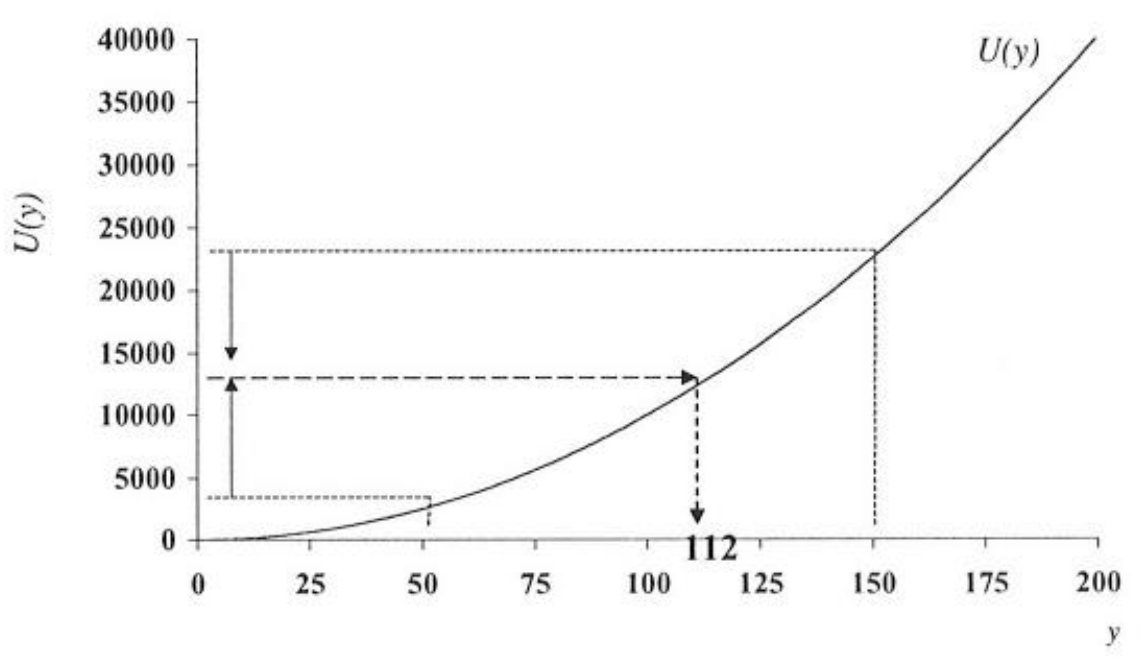

FIGURE 2a. Certainty equivalent for risk-loving bargainer $\mathbf{Y}$.

(Certainty equivalent for a 50-50 gamble over outcomes $y=50$ and $y=150$ is about 112.)

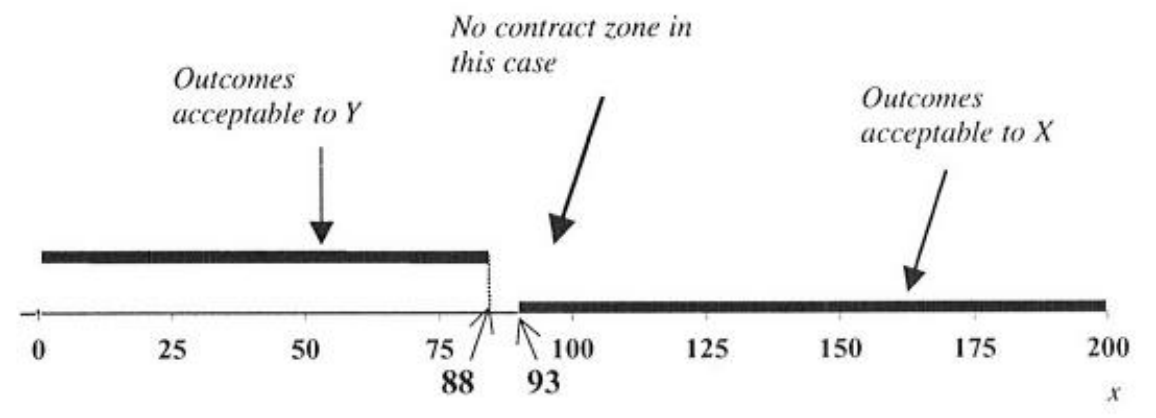

FIGURE 2b. Contract zone for risk-loving bargainer $\mathrm{Y}$ and risk-averse bargainer X (Figure 2 example).

(Note: Graph is over values of $x$, and $x+y=200$ in example.)

FIGURE 2a. Certainty equivalent for risk-loving bargainer $\mathrm{Y}$.

(Certainty equivalent for a 50-50 gamble over outcomes $y=50$ and $y=150$ is about 112.)

FIGURE 2b. Contract zone for risk-loving bargainer $Y$ and risk-averse bargainer $X$ (Figure 2 example). 
Risk-Averse Bargainer X: Pessimistic Expectations

(Certainty equivalent for a 75-25 gamble over outcomes $x=50$ and $x=150$ is about 70.)

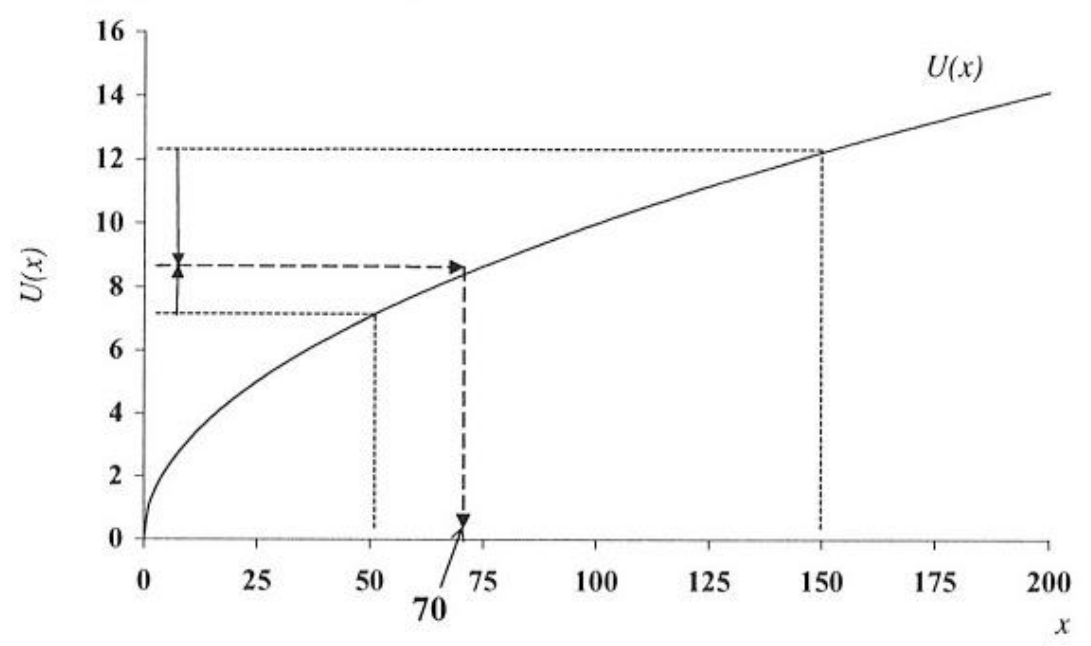

FIGURE 3a. Certainty equivalent.

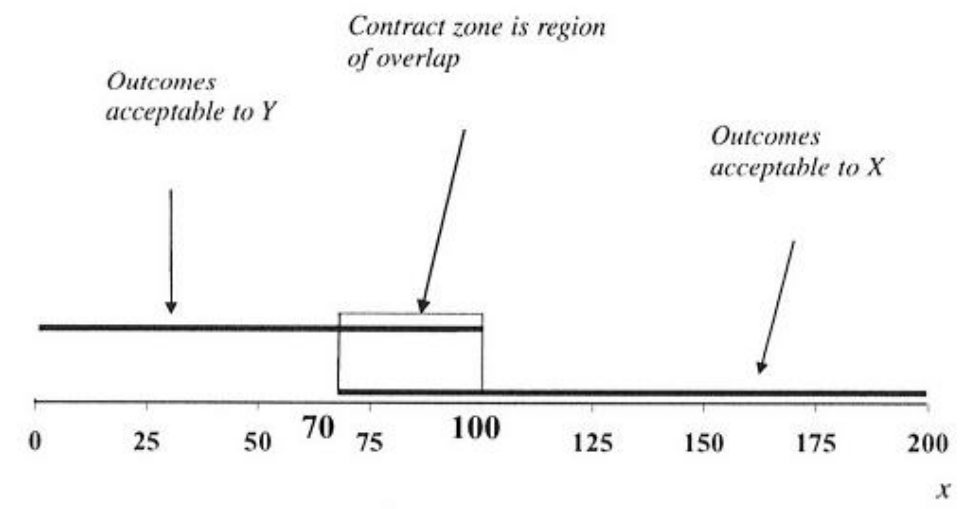

FIGURE 3b. Contract zone for risk-averse and pessimistic bargainer $\mathrm{X}$ and risk-neutral bargainer $\mathbf{Y}$ (Figure 3 example).

(Note: Graph is over values of $x$, and $x+y=200$ in example.)

FIGURE 3a. Certainty equivalent.

FIGURE 3b. Contract zone for risk-averse and pessimistic bargainer $X$ and risk-neutral bargainer $\mathrm{Y}$ (Figure 3 example). 


\section{A NOTE ON INCOME POSSIBILITY FRONTIERS}

These examples can also be used with an income possibility frontier (IPF) framework (e.g., Dixit and Skeath 1999). The two-bargainer IPF for a zero-sum bargaining game over a pie of size 200 is shown in Figure 4a. To use common terminology, one can refer to the certainty equivalents of the bargainers as threat points. The threat points are labeled $a$ and $b$ for bargainer $X$ and $Y$, respectively. Although the IPF framework does not typically state whether lower threat points can result from risk aversion or pessimism, the results from the previous section can be highlighted nonetheless.

I now re-examine the scenario from Figure 1 with the IPF framework. Risk aversion of just one bargainer, which would imply a threat point of less than half the pie, can be seen to skew the contract zone in favor of the risk-neutral bargainer. In general, the common threat point at the $(a, b)$ coordinate will lie to the left (right) of the $y=x$ line as bargainer $X(Y)$ is relatively more risk averse than his counterpart (assuming that risk neutrality implies an expected outcome of half the pie in the event of impasse). It is therefore easy to see that the risk-averse bargainer will likely experience worse bargaining outcomes, ceteris paribus.[10] In Figure 4b, I use the IPF to examine the scenario of Figure $2 b$, where bargainer $Y$ is risk loving and bargainer $X$ is risk averse. This example is highlighted because it generates the prediction of failed negotiations. On the IPF graph, this is reflected as a common threat point that lies strictly outside of the IPF. 


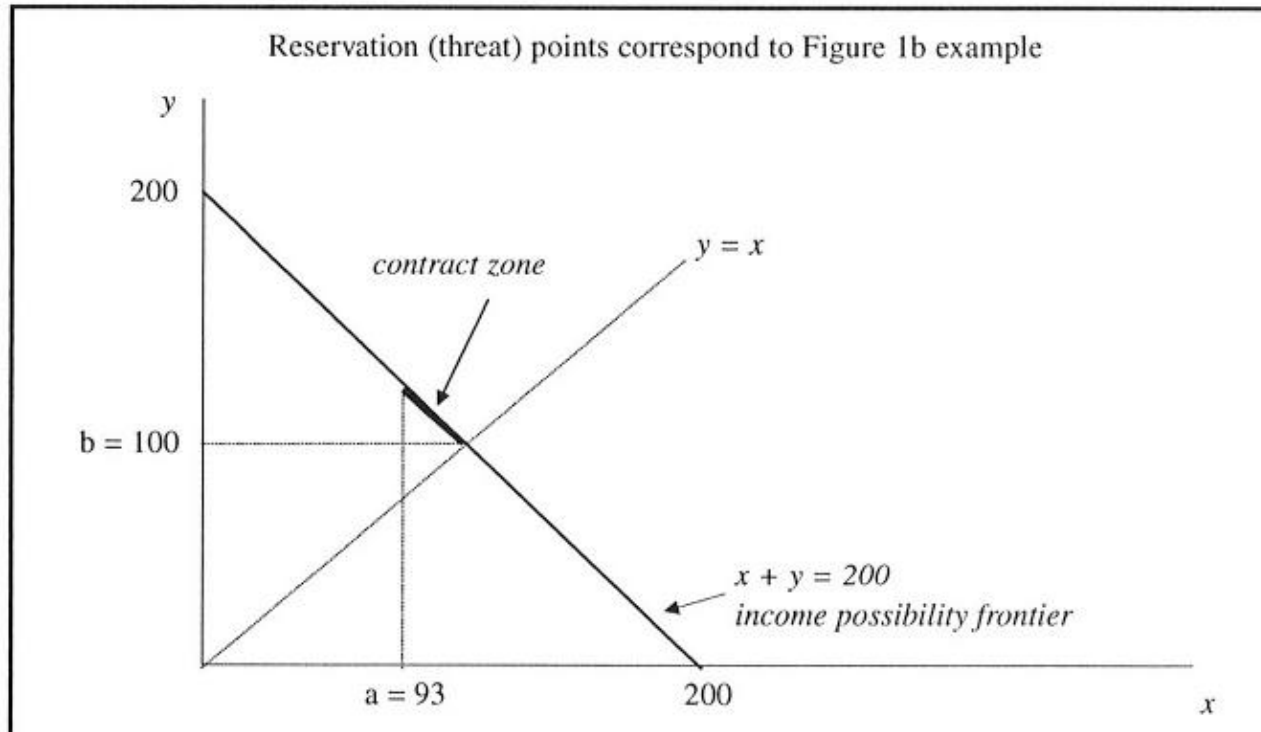

FIGURE 4a. Income possibility frontier.

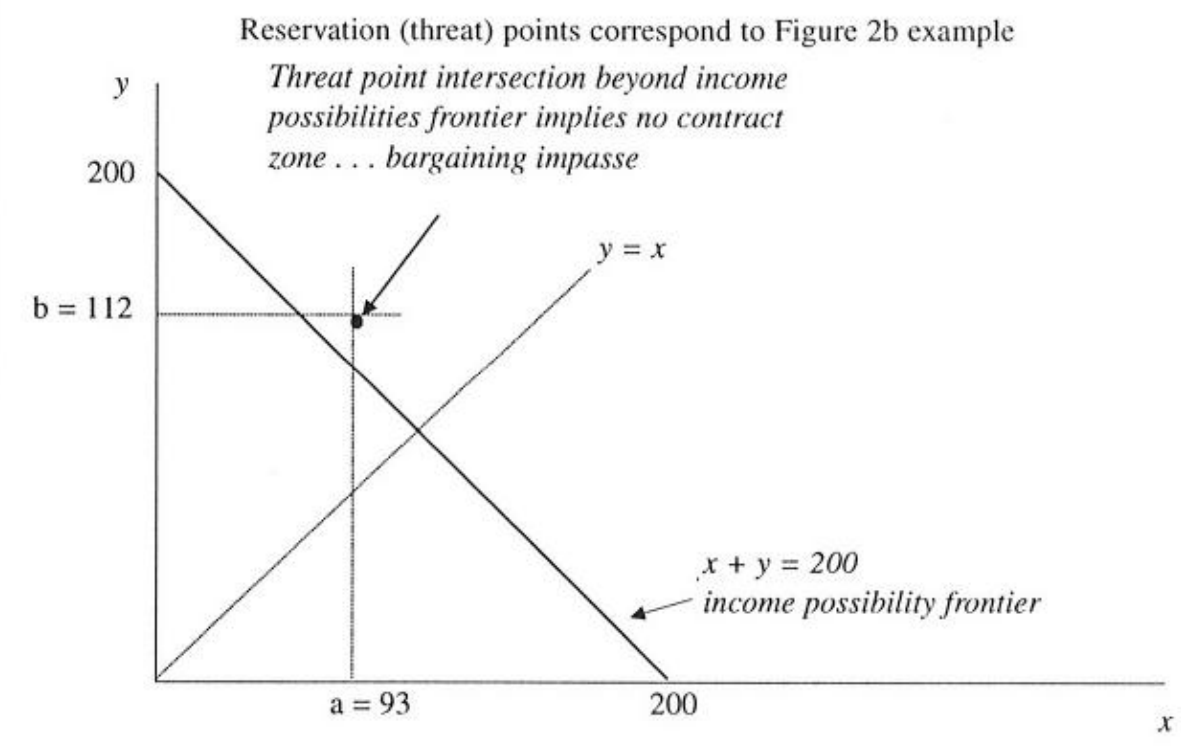

FIGURE 4b. Income possibility frontier and bargaining impasse.

FIGURE 4a. Income possibility frontier.

FIGURE 4b. Income possibility frontier and bargaining impasse.

Again, in these examples, the IPF framework itself does not distinguish between a threat point of $b=112$ that arises from optimism versus risk-loving preferences. Discussion leading up to the IPF graph and threat point locations can help highlight the different reasons for various locations of bargainer threat points. The IPF framework also highlights that a common threat 
point off the $y=x$ line implies an outcome favoring one particular bargainer, and a common threat point strictly outside the IPF implies failed negotiations. Although these examples do not speak of expectations explicitly, it is a clear implication that bargainers who are optimistic (and/or risk loving) are likely to experience better negotiated settlements as well as a higher incidence of failed negotiations by the same reasoning-both of these would increase a bargainer's threat point in the IPF framework.

\section{FINAL THOUGHTS}

It is clear that numerous examples can be created using this framework to show students how risk preferences or expectations, or both, would affect bargaining outcomes. In the process, students will be exploiting expected utility theory in a useful and, I hope, novel way. There are certainly issues that I have not dealt with in this article. First, one might ask if this is a reasonable way to model bargainer behavior and expectations. I have simplified the world to such an extent that I hope that there is still a useful decisionmaking environment to study. Bargaining is a very complicated process, and one that I do not claim to understand fully. However, it is not hard to convince most individuals that risk preferences and expectations are at least important items in determining bargaining outcomes. The comparative static analysis can therefore be useful to instruct and motivate further discussion from the students.

Second, expectations may not accurately reflect the true probability of such contingencies occurring. Although this may be true, it is still the case that the possibility of agreement at any given point in time is based on subjective probabilities more than true probabilities. It may also be the case that more than two outcome contingencies should be considered. The instructor can easily extend this framework to cover as many contingencies as desired. Of course, this complicates the analysis a bit, but students may view it as more realistic.

Finally, one must carefully avoid making false inferences regarding the welfare implications of bargaining outcomes in this framework. Outcomes where a risk-averse or pessimistic bargainer gets less than half the pie do not imply that the bargainer is worse off, per se, because outcomes in the contract zone are still preferable to receiving the certainty equivalent (or threat point).[11] Similarly, failed negotiations need not necessarily imply that bargainers are worse off. Bargaining impasse implies a mutual ex ante preference for playing the lottery of impasse (e.g., strike or arbitration) versus negotiating a settlement lower than their certainty equivalents. If, however, the impasse is a result of optimism (versus risk-loving behavior), then impasse is Pareto inefficient because of the bargainer's ( $s^{\prime}$ ) imperfect expectations regarding the impasse lottery. Unless equity considerations are explicitly incorporated into this analysis, one cannot Pareto rank the different outcomes that can result from various risk preferences or expectations combinations.

The merits of this framework for students versed in expected utility theory are nontrivial from my viewpoint. As a new class of applied problems is introduced, students are less likely to view expected utility theory as a useless or unrealistic way to characterize behavior. Furthermore, bargaining is a topic of interest in many applied economics classes, and it is also a topic with 
which students have likely had personal experience of some sort. Finally, the framework is simple and can be somewhat tailored to the level of sophistication of the students. A purely graphical analysis can be used, or the instructor can complement the graphical analysis with numeric solutions using specific or general functional forms to describe preferences.[12] It is my belief that such examples would have a long-term impact on students because they will continue to engage in bargaining situations over the course of their lives. Why not provide them a way of analyzing such real-life situations with the economics tools that they already possess?

\section{NOTES}

1. Babcock and Loewenstein (1997) also review the economics and psychology literature on the self-serving bias.

2. Although I have focused only on risk preferences and expectations, Rubinstein $(1982 ; 1985)$ focused on time preferences and cost of delay. His models show that costs of delay, or "impatience," will produce a certainty equivalent-as discussed in this article-in today's negotiations versus tomorrow's lottery. A more impatient bargainer in Rubinstein's framework will accept lower negotiated outcomes.

3. Although researchers have debated whether a larger contract zone implies a higher likelihood of negotiated agreements (Babcock, Loewenstein, and Wang 1995), it is simpler for instruction to assume that the probability of agreement is increasing in the size of the contract zoneinstructors may choose to entertain this line of discussion. It is intuitive, however, to at least assume that a positive contract zone implies more likely agreement than no contract zone (and the contract zone's location determines whom the outcome will likely favor), and so the arguments developed in this article still apply.

4. Students may be aware of the philosophy of win-win bargaining (or mutual gains bargaining or principled negotiations), which would seem to lessen the realism of win-loss bargaining examples. Although it may be true that not all negotiations are of a pure win-loss nature, it can be highlighted that there likely exists at least a component of any negotiations that is win-loss in nature (as suggested in Walton and McKersie 1991). The examples discussed in this article can then be related to the win-loss component of bargaining.

5. The line of reasoning using certainty equivalents was patterned after Farber and Katz (1979), and its application to risk preferences extends from Ehrenberg and Smith (2000, Appendix 13a).

6. This framework, as represented in Figure 1b, is not unlike the framework of Kuhn (1974), discussed in Herman (1998). It is assumed that only tactics of the bargainers can affect the outcome negotiated for a given contract zone, and so, by assuming that the midpoint of the contract zone will be the negotiated outcome, we assume that the bargainers are equally skilled in their tactics-notwithstanding their expectations and risk preferences.

7. For example, let bargainer $Y$ have utility function $U(y)=y^{\wedge} \sup 1 / 10^{\wedge}$. 10Bargainer $Y^{\prime} s$ certainty equivalent for the $50-50$ gamble over outcomes $y=50$ and $y=150$ is now $y=88$ 
(approximately). The midpoint of a contract zone with risk-averse bargainer $\mathrm{X}$, who has $\mathrm{U}(\mathrm{x})=$ $x^{\wedge}$ sup $1 / 2^{\wedge}=102.5$ (or $y=98.5$ ), which highlights an outcome in favor of the less risk-averse bargainer $\mathrm{X}$.

8. When considering these two different versions of pessimism, the two resulting certainty equivalents for a pessimistic bargainer $X$ will not be the same, except under risk neutrality, even though the expected value of the two lotteries is the same.

9. A referee has noted that one could also assume that there is uncertainty as to the payoff of a negotiated outcome and certainty about the payoff should negotiations fail. An example noted by the referee is the negotiation over the take-over of a company, where the value of the company in the event the negotiations succeed is uncertain. In such instances, risk aversion and/or pessimism will likely increase the probability of bargaining impasse and also lower the price the bargainer would pay for the company.

10. As before, I simplify the analysis by assuming that the ultimate negotiated outcome would occur at the midpoint of the contract zone. Dixit and Skeath (1999) developed a framework that implies that a relatively better bargainer (e.g., a bargainer possessing better tactics) would negotiate a more favorable outcome for a given contract zone.

11. Yet it is still the case that risk aversion and pessimism cause lower certainty equivalents, and so the analysis here is perhaps more complex than at first glance. This point was brought to my attention by an astute referee.

12. For example, the instructor could base examples on preferences of the form $U(x)=x^{\wedge}$ sup $a^{\wedge}$, where [alpha] $>0$. With this general form, risk-averse bargainers are those for whom [alpha] $<1$, whereas risk lovers would have [alpha] $>1$ (with risk-neutral bargainers having [alpha] $=1$ ).

\section{REFERENCES}

Babcock, L., and G. Loewenstein. 1997. Explaining bargaining impasses: The role of selfserving biases. Journal of Economic Perspectives 11 (1): 109-26.

Babcock, L., G. Loewenstein, S. Issacharoff, and C. Camerer. 1995. Biased judgments of fairness in bargaining. American Economic Review 85 (5): 1337-43.

Babcock, L., G. Loewenstein, and X. Wang. 1995. The relationship between uncertainty, the contract zone, and efficiency in a bargaining experiment. Journal of Economic Behavior and Organization 27 (3): 475-85.

Crawford, V. 1982. Compulsory arbitration, arbitral risk and negotiated settlements: A case study in bargaining under imperfect information. Review of Economic Studies 49:69-82.

Dixit, A., and S. Skeath. 1999. Games of strategy. 1st ed. New York: W.W. Norton. 
Ehrenberg, R., and R. Smith. 2000. Modern labor economics. 7th ed. Reading, Mass.: Addison Wes-Icy Longman.

Farber, H., and H. Katz. 1979. Interest arbitration, outcomes and the incentive to bargain. Industrial and Labor Relations Review 33 (1): 55-63.

Farber, H., M. Neale, and M. Bazerman. 1990. The role of arbitration costs and risk aversion in dispute outcomes. Industrial Relations 29 (3): 361-84.

Farmer, A., and P. Pecorino. 1994. Pretrial negotiations with asymmetric information on risk preferences. International Review of Law and Economics 14 (3): 273-81.

Farmer, A., P. Pecorino, and V. Stango. 2001. Asymmetric information and excessive optimism as causes of bargaining failure: Evidence from major league baseball arbitration. Working Paper \#00-08-04. University of Alabama.

Herman, E. 1998. Collective bargaining and labor relations. 4th ed. Upper Saddle River, N.J.: Prentice-Hall.

Kuhn, A. 1974. The logic of social systems. A unified, deductive system-based approach to social science. San Francisco, Calif.: Jossey-Bass.

Murnighan, K., A. Roth, and F. Schoumaker. 1988. Risk aversion in bargaining: An experimental study. Journal of Risk and Uncertainty 1 (1): 101-24.

Neale, M. A., and M. Bazerman. 1985. The effects of framing and negotiator overconfidence on bargaining behaviors and outcomes. Academy of Management Journal 28 (1): 34-49.

Priest, G. L., and B. Klein. 1984. The selection of disputes for litigation. Journal of Legal Studies 13 (1): 1-55.

Rubinstein, A. 1982. Perfect equilibrium in a bargaining model. Econometrica 50 (1): 97-109. 1985. A bargaining model with incomplete information about time preferences. Econometrica 53 (3): 1151-72.

Shavell, S. 1982. Suit, settlement, and trial: A theoretical analysis under alternative methods for the allocation of legal costs. Journal of Legal Studies 11 (January): 55-81.

Walton, R., and R. McKersie. 1991. A behavioral theory of labor negotiations. 2nd ed. Ithaca, N.Y.: ILR. 